\title{
A UTILIZAÇÃO DA CONTABILIDADE NA GESTÃO DOS PEQUENOS NEGÓCIOS DE RECURSOS PESQUEIROS DO AMAZONAS
}

\section{ARTIGO ORIGINAL}

LIMA, Júlia Clemente de ${ }^{1}$, MENDONÇA, Samily Balieiro de ${ }^{2}$, ROBERTO, José Carlos Alves ${ }^{3}$, SERRA, Meg Rocha da Cunha ${ }^{4}$, LOPES, Nelânia Ferreira ${ }^{5}$

LIMA, Júlia Clemente de. Et al. A utilização da contabilidade na gestão dos pequenos negócios de recursos pesqueiros do Amazonas. Revista Científica Multidisciplinar Núcleo do Conhecimento. Ano. 06, Ed. 11, Vol. 05, pp. 145-162. Novembro 2021. ISSN: 2448-0959, Link de acesso: https://www.nucleodoconhecimento.com.br/contabilidade/recursos-pesqueiros, DOI: 10.32749/nucleodoconhecimento.com.br/contabilidade/recursos-pesqueiros

\section{RESUMO}

A contabilidade é uma área que tem como objetivo principal o fornecimento de dados importantes sobre todo o processo que ocorre uma cadeia de controle dentro de uma organização: controle dos gastos, custos, lucros e perdas, assim como outras informações que são necessárias para que a gestão da movimentação financeira seja adequada e controlada. No contexto da cadeia de recursos pesqueiros, esse mecanismo se torna viável para as operações, já que é envolvida por diversos procedimentos e operações os quais envolvem questões contábeis, tendo em vista a quantidade de custos fixos e dívidas associadas a uma operação de pesca comercial. Assim sendo, o presente trabalho buscou responder a seguinte questão: de que forma a contabilidade pode influenciar na organização da cadeia

\footnotetext{
${ }^{1}$ Graduanda do curso de Contabilidade.

${ }^{2}$ Graduando do curso de Contabilidade.

${ }^{3}$ Orientador. Mestre em Engenharia de produção. Especialista Logística empresarial. Graduado em Administração com Ênfase em Marketing.

${ }^{4}$ Orientadora. Mestra em Engenharia de Processos Industriais pela UFPA, especialista em Controladoria e Auditoria Contábil pelo Ciesa, Graduada em Ciências Contábeis pelo Centro Universitário do Norte. Graduada em Ciências Econômicas pelo Centro Universitário do Norte.

${ }^{5}$ Orientadora. Especialista em Auditoria Contábil, Financeira e Tributaria e Graduada em Ciências Contábeis.
}

RC: 100892

Link de acesso: https://www.nucleodoconhecimento.com.br/contabilidade/recursospesqueiros 
produtiva dos recursos de pequenos negócios pesqueiros no Amazonas? Nesse sentido, o objetivo geral desta pesquisa foi apresentar o impacto que a utilização da contabilidade pode exercer na gestão dos recursos pesqueiros no Amazonas. O desenvolvimento do presente artigo deu-se através da utilização do meio de pesquisa bibliográfico, de fins exploratórios e natureza aplicada. Sendo possível pesquisas na base de dados eletrônica Scielo (Scientific Electronic Library Online). Os principais resultados apresentados nesse estudo foram identificados através da busca pela resposta à pergunta problema, com a seleção e análise de estudos e informações que mostraram que a utilização da contabilidade na gestão dos recursos pesqueiros pode influenciar no desenvolvimento e crescimento de pequenos negócios pesqueiros locais. Foi concluído, de acordo com a literatura pesquisada, que grande parte dos responsáveis por pequenos negócios pesqueiros no Amazonas não possuem conhecimento e consciência de que a utilização de recursos contábeis pode influenciar de forma positiva o lucro obtido nas vendas e que isso pode ser relevante para o crescimento do pequeno negócio.

Palavras-chave: Contabilidade, recursos pesqueiros, gestão, cadeia.

\section{INTRODUÇÃO}

De acordo com Fonseca et al. (2014) a contabilidade é uma área que tem como objetivo principal o fornecimento de dados importantes sobre todo o processo que ocorre uma cadeia de controle dentro de uma organização, controle dos gastos, custos, lucros e das perdas, assim como outras informações que são necessárias para que a gestão da movimentação financeira seja adequada e controlada. Por isso, o presente artigo objetivou-se em apresentar sobre o impacto que a utilização da contabilidade pode exercer na gestão dos recursos pesqueiros no Amazonas. Pois, os recursos pesqueiros são considerados como fonte de renda familiar, pois geram trabalhos e proporcionam alimentação e cada vez esses recursos se tornam mais necessários para a população local.

RC: 100892

Link de acesso: https://www.nucleodoconhecimento.com.br/contabilidade/recursospesqueiros 
De acordo com Severino (2016), o problema é algo que envolve uma dificuldade prática ou teórica, para qual deve-se encontrar uma solução. Nesse sentido, originase a questão problema utilizada no estudo, de que forma a contabilidade pode influenciar na organização da cadeia produtiva dos recursos de pequenos negócios pesqueiros no Amazonas?

Utilizou-se também os objetivos específicos para o direcionamento de informações qualitativas para o embasamento da pesquisa. Através dos objetivos estabelecidos foi possível relacionar a relevância da utilização de ferramentas contábeis na gestão dos recursos pesqueiros, com a descrição dos segmentos que compõem a cadeia produtiva do pescado, sendo apresentado as ferramentas contábeis para a gestão eficiente dos pequenos negócios pesqueiros. Os serviços contábeis se tornam importantes no contexto da cadeia de recursos pesqueiros, pois a cadeia possui diversos procedimentos e operações as quais são necessárias questões contábeis.

A pesquisa justifica-se pela contabilidade no âmbito dos recursos pesqueiros ser uma estratégia viável para o crescimento comercial dessa área. Visto que os pescadores que são a base da cadeia dos recursos pesqueiros são, em grande parte, os mais afetados pela ausência de conhecimento das ferramentas contábeis, o que pode ser um fator impactante para o desenvolvimento e visão de empreendimento retardado. O que mostrou a importância do estudo acerca do tema, para melhor compreensão e aplicabilidade.

O desenvolvimento do presente artigo deu-se através da utilização do meio de pesquisa bibliográfico, de fins exploratórios e natureza aplicada. Sendo possível pesquisas na base de dados eletrônica Scielo (Scientific Electronic Library Online).

\section{FUNDAMENTAÇÃO TEÓRICA}

Segundo Lakatos (2017) o referencial teórico define os conceitos-chave em uma pesquisa, com objetivo de descrever sobre as teorias relevantes com base em uma revisão da literatura, permitindo a interpretação a partir de pesquisas. 


\subsection{HISTÓRIA E EVOLUÇÃO DOS RECURSOS PESQUEIROS}

O recurso pesqueiro é abundante na região amazônica é considerado a principal fonte de abastecimento alimentar, mudanças relacionadas ao setor pesqueiro aconteceram nas últimas décadas. Como apresentado por Alvarado (2016) sendo exemplificado a evolução dos meios pesqueiros através da relação e comparação entre os custos que envolvem a prática de investimento, gestão e administração com os benefícios que o desenvolvimento realizado de forma adequada ao longo prazo. Sendo assim, ao analisar o custo e benefício é possível traçar objetivos e decisões sendo levado em consideração prós e contra.

Segundo Santos et al., (2012) a pesca, também é uma prática de captura de peixes, água doce ou salgada, normalmente com vara, linha e anzol. Assim como a caça, a pesca surgiu como um meio de fornecer alimentos para a sobrevivência. A "pesca" pode ser oficialmente definida como o processo de captura de peixes selvagens ou outras espécies aquáticas nas águas, seja para o sustento, como negócio ou por esporte. A pesca de comércio é caracterizada pela venda de peixes, enquanto a pesca recreativa corresponde a prática de pesca por esporte, tendo a possibilidade de o praticante ter o objetivo de comer ou não os peixes.

De acordo com Carneiro (2017) a pesca era uma fonte essencial de alimento na Préhistória e tornou-se uma atividade comercial na Antiguidade. A pesca de alto mar surgiu no século $\mathrm{XV}$, mas realmente disparou com a chegada dos barcos a vapor no século XIX. Os arrastões mais poderosos eram capazes de puxar redes maiores. A pesca recreativa, reservada às classes abastadas no século XVIII, tornou-se mais acessível à medida que os avanços tecnológicos possibilitaram a produção de melhores equipamentos a um custo menor.

As técnicas de pesca variam de acordo com o tipo de peixe a ser capturado, mas não evoluíram muito ao longo dos séculos. Hoje, de acordo com Santos et al., (2012) os métodos tradicionais são usados ao lado de técnicas mais industriais. Redes, armadilhas e canas de pesca são usadas universalmente e esses 
equipamentos evoluíram com 0 avanço da tecnologia ou permaneceram dependentes dos recursos locais e do conhecimento em regiões intocadas pela industrialização.

Segundo Alvarado (2016) a pesca recreativa pode ser feita de várias maneiras, incluindo a coleta manual, arpão, rede, armadilhagem e pesca à linha - o processo de pescar peixes com anzóis, linhas e varas ou varas. A maioria das pessoas, porém, considera a pesca como o ato de pegar peixes com anzol e linha. Você pode usar uma vara ou haste e molinete para fazer isso. Varas e molinetes para pesca incluem roupas de pesca com mosca, com giratória e roupas com isca. Outras formas de captura de peixes, como arpões ou redes, variam conforme o local e às vezes são proibidas por lei.

A pesca comercial corresponde a captura de pescados para a obtenção de lucros, ou seja, é uma prática realizada com objetivo final de vendas. Através desse tipo de pesca é possível fornecer alimentos aquáticos para diversas regiões, a nível mundial. Essa atividade feita em grande escala também é conhecida como pesca industrial, as principais indústrias pesqueiras não pertencem apenas a grandes corporações, mas também a pequenas famílias.

De acordo com Viana (2013) os recursos pesqueiros são estoques de espécies-alvo e seu ambiente, que podem ser legalmente capturados pela pesca. Às vezes, pode ser considerado como incluindo também o habitat de tais recursos. Sendo assim, um recurso pesqueiro se refere aos organismos que habitam no meio aquático, que normalmente são alvos da pesca e da alimentação da população. Para que um organismo seja considerado como recurso pesqueiro deve ser levado em consideração a disponibilidade e seu valor, pois a disponibilidade de forma abundante torna possível que seja alvo da pesca e seu valor. Os dois fatores são importantes para obter lucro. 


\subsection{LEIS E POLÍTICAS SOBRE OS RECURSOS PESQUEIROS NO BRASIL}

A Lei № 11.959, de 29 de junho de 2009, dispõe sobre a Política Nacional de Desenvolvimento Sustentável da Aquicultura e da Pesca, regula as atividades pesqueiras. De acordo com a Tabela 1 que apresenta as leis e decretos nacionais.

Segundo Azevedo (2012) o Ministério da saúde passou a ser responsável por coordenar e analisar as atividades relacionadas aos recursos pesqueiros, sendo incluído nesse conjunto as atividades de pesquisas e extensões, o supervisionamento das estatísticas, os processos de licença e permissão para realização das práticas pesqueiras comerciais. Além disso, também é de cunho no Ministério da saúde a fiscalização da sanidade dos produtos de pescas, dado a importância da qualidade dos alimentos para a saúde da população. Porém, ainda permanece de responsabilidade do MPA o ordenamento da aquicultura.

Quadro 1 Leis brasileiras gerais relacionadas aos recursos pesqueiros.

\section{Dec.-Lei no Proteção e estímulos à pesca 221/1967}

Lei $\mathrm{n}^{\circ} 7.643$ / Proíbe a pesca de cetáceos nas águas jurisdicionais brasileiras 1987

Lei $\mathbf{n}^{\circ} \mathbf{1 0 . 8 4 9} /$ Programa Nacional de Financiamento da Ampliação e Mode 2004

Lei $\mathrm{n}^{\circ}$ 11.524, Elementos sobre vários assuntos; uma autoriza indenização de 24/09/2007 àqueles que entregarem redes de espera do tipo caçoeira, usado para a captura de lagostas (arts. 16-19)

Lei $n^{\circ} 11.958$ / Transforma a Secretaria Especial de Aquicultura e pesca da 2009 Presidência da República em Ministério da Pesca e aquicultura Lei $\mathrm{n}^{\circ} 11.959$ / Institui a Política Nacional de Desenvolvimento Sustentável da 2009 Aquicultura e da Pesca e regula as atividades pesque 
Dez. $\mathbf{n}^{\circ}$ 4.810, Normas para operação de embarcações pesqueiras nas zonas de 18/08/2003 brasileiras de pescas

Dez. $\mathrm{n}^{\circ}$ 4,895, Uso de corpos d'água de domínio da União para fins de de 25/ 11/2003 aquicultura

Dez. $\mathrm{n}^{\circ}$ 5,583, Autoriza o lbama estabelecer normas para gestão do uso de 16/ 11/2005 sustentável dos recursos pesqueiro

Dez. $\mathrm{n}^{\circ} 6.981$ / Atuação conjunta dos Ministérios da Pesca e Aquicultura e fazer 2009

Porta. MPA / Sistema de Gestão Compartilhada do Uso Sustentável dos MMA n' 2/2009 Recursos Pesqueiros

Fonte: Schneider (2010).

\subsection{A IMPORTÂNCIA DA CONTABILIDADE PARA GESTÃO}

A pesca passou a ser uma das principais fontes geradoras de renda para as famílias ribeirinhas, por isso é importante medir e controlar o desempenho econômicofinanceiro e de cada atividade produtiva. Segundo Fonseca et al. (2014) a utilização das ferramentas disponíveis pela contabilidade proporcionou diversos mecanismos para a facilidade nas escolhas realizadas pelos proprietários, assim como a evolução da economia proporcionou a compreensão da necessidade de se obter um diferencial, para possibilidade de crescimento dos negócios. O que gerou maior credibilidade nos recursos contábeis dentre as negociações de mercado.

Sendo assim, a contabilidade junto a cadeia produtiva dos recursos pesqueiros pode ser definida como uma ferramenta que possibilita a autonomia do sobre os agentes envolvidos na cadeia dos recursos pesqueiros. Sendo incluído o conhecimento e consciência dos processos econômicos, que pode intervir na vida social de algumas comunidades e cidades ribeirinhas pesqueiras.

Segundo Alves (2017) a contabilidade tem por finalidade a utilização de ferramentas para registros numéricos, sendo referidos dados completos das finanças na área 
empresarial. Possui o objetivo de apresentar recursos e dados que interpretem as estatísticas lógicas numéricas, fornecendo informações de adequação ou irregularidade no desenvolvimento contábil. Ela é dividida em duas áreas, a financeira e empresarial, que respectivamente correspondem a procedimentos de pagamentos de compra e venda gerando um balanço para fins fiscais e comerciais e a utilização de cálculos dos custos gerados.

Por isso, de acordo com Silveira, Cardoso e Costa (2018), conhecer sobre essa ferramenta e analisar a influência que ela exerce no desempenho do empreendimento e em todos os fatores que envolvem os processos de contabilidade é fundamental para a atualidade da gestão moderna. Além disso, ela introduziu diversas modificações na forma de administrar um negócio, acompanhando proporcionalmente o mercado cada vez com uma maior competitividade e exigente com as empresas e organizações que precisam estar cada vez mais capacitadas para acompanhar a evolução dos processos gerenciais.

\subsubsection{A CONTABILIDADE NOS PEQUENOS NEGÓCIOS PESQUEIROS}

De acordo com Bugarim e Oliveira (2014) é importante entender que a contabilidade não serve apenas para declaração de imposto de renda, pois o serviço dos profissionais é essencial para qualquer negócio. Por isso, é essencial que os contadores dessa área estejam atentos a estudos e legislações que forneçam conteúdo para obtenção de mais conhecimento dessa otimização dos processos.

Para Fonseca et al. (2014) compreender através de investigações e análises científicas sobre as vantagens da contabilidade é necessário para o crescimento das empresas e da capacitação dos empreendedores. Com os processos da atuação da contabilidade os procedimentos são facilitados e os problemas podem ser solucionados com rapidez, além disso, a gestão passa ser mais planejada, diminuindo possíveis erros que elevam os gastos, além de possibilitar segurança 
nas finanças e documentações, o que se torna importante mesmo para pequenos negócios.

De acordo com Almeida (2016) a contabilidade para pequenos negócios é feita mantendo um registro completo de todas as receitas e despesas e extraindo com precisão as informações financeiras das transações comerciais. Essa é uma tarefa necessária que pode ajudar os proprietários de negócios a rastrear e gerenciar seu dinheiro de forma eficaz, especialmente durante os estágios iniciais. Além de mantêlo informado sobre o desempenho dos recursos, a contabilidade de pequenos negócios também ajuda na geração de faturas e no preenchimento de pagamento.

Além disso, a análise de transações financeiras também pode ser incluída nas ferramentas que a contabilidade pode exercer nos recursos pesqueiros. Segundo Birk; Fedato e Pires (2020) o processo de contabilidade começa com a análise das transações financeiras e a inserção das pertencentes à movimentação comercial no sistema contábil. A primeira etapa do processo de contabilidade envolve a preparação dos documentos de origem. Um documento de origem ou documento comercial serve como base para registrar uma transação.

Segundo Chupel; Sobral e Barella (2014) às transações comerciais são registradas em um diário (também conhecido como Livros de lançamento original) em ordem cronológica, usando o sistema de contabilidade por partidas dobradas. Os lançamentos contábeis manuais podem incluir duas contas, débito e crédito. Com isso, para tornar este processo mais fácil, os contadores usam um diário especial para registrar transações recorrentes, como compras, vendas, recebimentos de caixa etc. as transações que não podem ser incluídas nos diários especiais são registradas no diário geral. 


\subsection{MECANISMOS DA CONTABILIDADE PARA OS RECURSOS PESQUEIROS}

Os processos utilizados na contabilidade são usados em diversos ambientes que envolvam fatores financeiros, pois ela dá suporte na gestão administrativa das organizações e nas empresas de todos os tipos de porte. Isso pode ser explicado por Fonseca et al. (2014) que descreve que a contabilidade é o fornecimento de dados importantes sobre todo o processo que ocorre uma cadeia de controle dentro de uma organização, controle dos gastos, custos, lucros e das perdas, assim como outras informações que são necessárias para que a gestão da movimentação financeira seja adequada e controlada

Segundo Santos et al. (2016) esses mecanismos se tornam importantes no contexto da cadeia de recursos pesqueiros. Pois, muito dessa contabilidade se torna viável para as operações pesqueiras, já que elas giram em torno das principais compras que estão envolvidas. Como as licenças de pesca, que variam em cada estado, podendo haver limitação à captura a um determinado tipo de peixe e limitar as atividades de pesca apenas ao titular da licença, ou ao titular da licença e certo número de membros da tripulação. Com isso, é designada a área disponível para pesca e quando ela pode ser pescada.

Segundo Yamamoto et al. (2021) a cadeia produtiva de recursos pesqueiros é envolvida por diversos procedimentos e operações as quais são necessárias para envolver questões contábeis, havendo muitos custos fixos e dívidas associadas a uma operação de pesca comercial. Assim como também há algumas contas de ativos fixos diferentes, como o barco de pesca, mas também há contas de eletrônicos para embarcações, equipamentos de processamento de peixes e artes de pesca. E então existem algumas despesas únicas, como combustível para o barco, mantimentos para alimentar a tripulação, despesas com iscas e despesas com gelo. 
A única área da contabilidade que é mais fácil para uma operação de pesca são as contas a receber. A maioria vende o produto para uma única empresa de processamento de pescado, o que significa que há apenas uma conta a receber para tratar. Algumas alternativas são vendas diretas a casas e restaurantes, mas no geral, o número de clientes é bastante limitado. No entanto, ao que se refere sobre os mercados pesqueiros, o da Amazônia pode se tornar destaque, pois a pesca na região amazônica destaca-se em relação às demais regiões brasileiras, por possuir uma abundante variedade de espécies e por ser um serviço de dependência para os indivíduos dessa região.

\subsubsection{OS MECANISMOS CONTÁBEIS E OS PESCADORES}

De acordo com Santos et al. (2016) muitos pescadores consideram que o dinheiro adquirido pela pesca não é suficiente para que eles consigam se estabilizar profissionalmente, para que consigam crescer. No entanto, em alguns casos isso se explica pois muitos desses pescadores não são adeptos a supervisão de custo, pois eles não possuem conhecimento básico em contabilidade, para que consigam utilizar os controles das atividades econômicas.

Nesse sentido, Freitas et al. (2016) apresenta que os pescadores que utilizam os recursos oferecidos pelos procedimentos contábeis, acabam tendo o controle dos custos de suas atividades. O que possibilita que esse profissional tenha noção da sua renda, sendo possível com auxílio de um contador, que ele consiga desenvolver uma visão crítica sobre o controle eficiente das finanças. Além disso, o controle contábil auxilia a ter um controle mais efetivo de gastos. Isso porque além de pagar menos impostos e ter um lucro maior, tendo em vista que o profissional contábil auxilia o controle de gastos, arrecadações e expectativas do mercado.

Sendo assim, segundo Santos et al. (2016) a contabilidade se constitui para os pescadores como um instrumento de controle e gestão de vital importância no processo de escolhas internas e a projeção do negócio tendo em vista o seu crescimento no mercado. Pois, se o pescador não possuir conhecimentos e noções 
de contabilidade poderá prejudicar o andamento dos seus negócios, dado a falta de gerenciamento e controle financeiro. Pois, uma contabilidade devidamente gerida permite que os custos incorridos, as deduções derivadas da operação e os rendimentos deles sejam obtidos de forma unificada, facilitando o segmento das obrigações mensais e permite obter informações oportunas e confiáveis para a tomada de decisões.

O estudo de Leite; Matos e Araújo (2019) teve como objetivo aplicar o controle dos custos e gerenciar o caixa para que os valores cobrados pelos pescadores sejam proporcionais e adequados ao serviço. Foi possível avaliar que a utilização das informações contábeis, proporcionam não apenas controle nos custos, mas como também possui a finalidade de gerenciar o caixa e os demais processos de venda com vantagens na competitividade. Todos esses procedimentos podem fornecer $\mathrm{e}$ auxiliar na lucratividade e rentabilidade do associado.

Sendo assim, apesar dos serviços de contabilidade não serem obrigatórios por lei aos pescadores, o uso das ferramentas contábeis pode fornecer inúmeros benefícios e vantagens. Entre a avaliação do custo real de cada produto e serviço, da logística de preço de venda e entre outras importantes para a gestão de controle dos negócios.

\subsection{ANÁLISE DOS SEGMENTOS QUE COMPÕEM A CADEIA PRODUTIVA}

Segundo Pereira et al. (2010) a cadeia de produção é o conjunto de atividades necessárias para levar um produto ou serviço desde sua concepção até o cliente final. Isso inclui atividades como design, produção, marketing, distribuição e serviços de suporte. As cadeias de valor incluem mercados locais, regionais e globais. As principais atividades em uma cadeia de valor da pesca podem incluir pesca, produção de aquicultura, processamento, transporte, atacado e marketing de varejo. Como apresentado na Figura 1. 
Para Silva et al. (2014) durante a cadeia produtiva é comum que a perda e o desperdício de alimentos ocorram em qualquer dos níveis da cadeia de valor da pesca e da aquicultura. Entender o porquê e identificar onde ocorre o desperdício é crucial para fornecer à gestão o controle de decisão de informações que podem reduzi-lo e evitá-lo. A redução do desperdício está se tornando cada vez mais importante à medida que a demanda por peixes aumenta.

De acordo com a análise criteriosa do mecanismo envolvido na cadeia dos recursos pesqueiros se torna essencial a contribuição do profissional de Ciências Contábeis sobre as dinâmicas socioeconômicas existentes nessa cadeia produtiva. Pois segundo Paiva et al. (2020) a ação desse profissional segue como um suporte essencial, pois os pescadores não conhecem o valor do trabalho desse profissional, desconhecem suas competências e habilidades, assim como seu poder de transformação a partir do conhecimento técnico diluído a partir da prestação de informação precisa e simples.

RC: 100892

Link de acesso: https://www.nucleodoconhecimento.com.br/contabilidade/recursospesqueiros 
Figura 1 Cadeia produtiva de pescado.

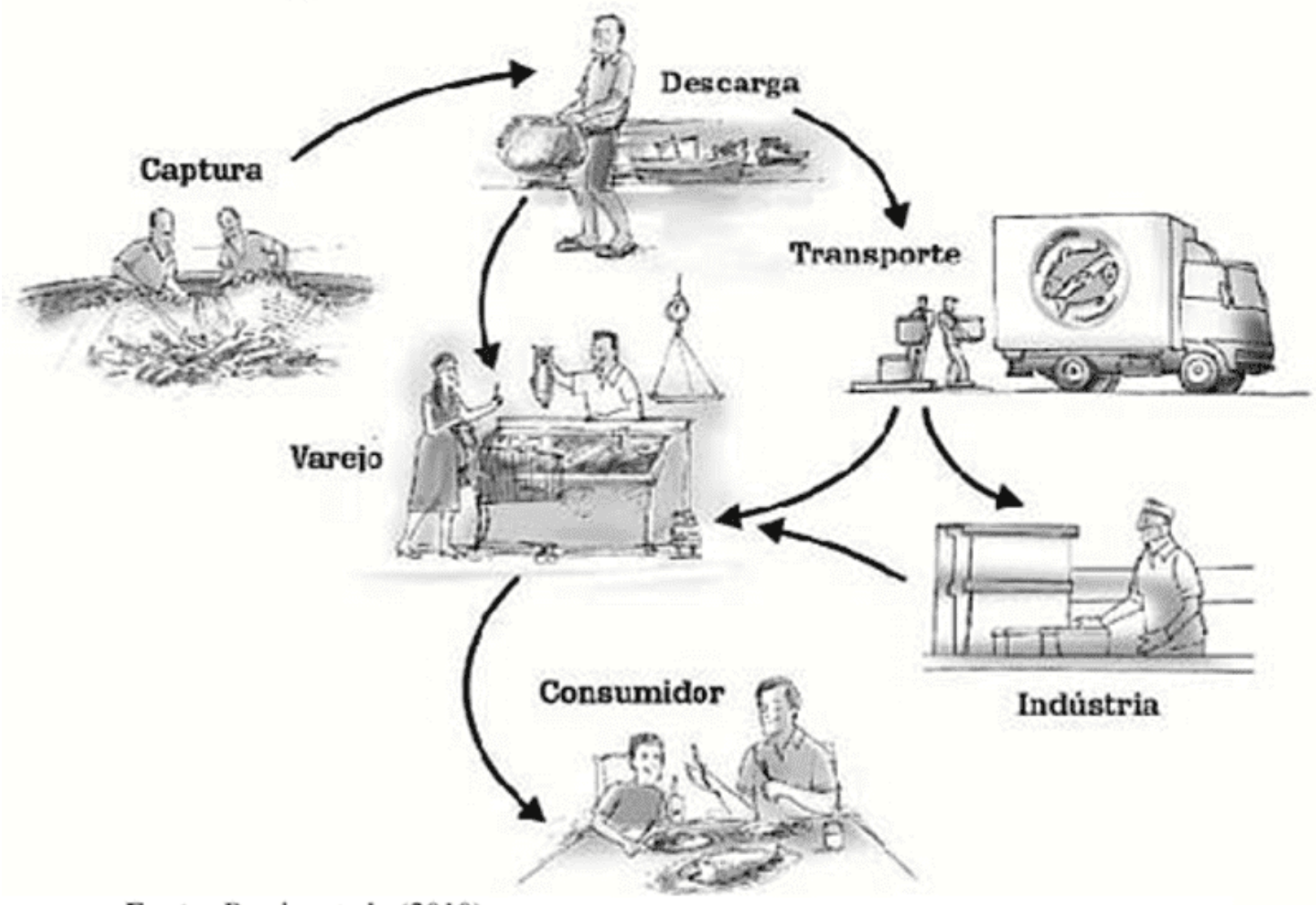

Fonte: Pereira et al., (2010).

Fato a ser considerado para o sucesso profissional nos territórios regionais, porém há que se considerar a linguagem cabocla como diferencial para comunicar-se com esses sujeitos sociais que possuem baixo nível de escolaridade e necessita de informações claras, as quais um contador possui maior compreensão.

\subsection{CADEIA DOS RECURSOS PESQUEIROS NO AMAZONAS}

De acordo com Oliveira et al. (2010) a pesca nessa região é fundamental para a subsistência de inúmeras famílias ribeirinhas, já que a alimentação dessas comunidades tem como base a pesca e caça. No entanto, esse tipo de pesca vem cada vez mais sendo substituído pelo método comercial, onde os pescadores realizam as atividades de pesca com o intuito de vendas e exportações. Esses

RC: 100892

Link de acesso: https://www.nucleodoconhecimento.com.br/contabilidade/recursospesqueiros 
pescadores, muitas vezes acabam sendo menos proveitosos dado a falta de recursos estruturais para armazenamento e transporte adequado dos peixes.

Segundo Souza (2010) esses fatores fazem com que haja uma cadeia entre o pescador artesanal até a chegada ao consumidor final. Por isso, no estado do Amazonas, o processo que envolve a pesca e comércio do pescado acaba sendo associado à alimentação da região e os mecanismos de logística também quanto ao mercado. O que faz necessário a participação de diversos agentes na cadeia do pescado, conforme apresentado na Figura 2.

Sendo assim, segundo Paiva et al. (2020) a atividade pesqueira passa por um processo de inúmeras mudanças em relação ao comércio, dada a demanda regional elevada quanto ao consumo de peixes. Por isso, se torna importante que os pescadores estejam mais atentos aos processos de controle e gestão, para que consigam potencializar cada vez mais suas atividades comerciais.

Por isso, a contribuição da contabilidade para as cadeias produtivas sobre os recursos pesqueiros se torna necessária, para que haja a aplicação dos mecanismos profissionais que possibilitem uma maior compreensão e análise sobre os processos financeiros que envolvem a cadeia pesqueira. O que, segundo Souza et al. (2015) proporciona maior conhecimento para os pescadores, atuando como auxílio na melhor visão sobre os valores de cada produto no mercado regional e até mesmo a nível nacional.

RC: 100892

Link de acesso: https://www.nucleodoconhecimento.com.br/contabilidade/recursospesqueiros 
Figura 2 Fluxograma da cadeia produtiva dos peixes no Amazonas.

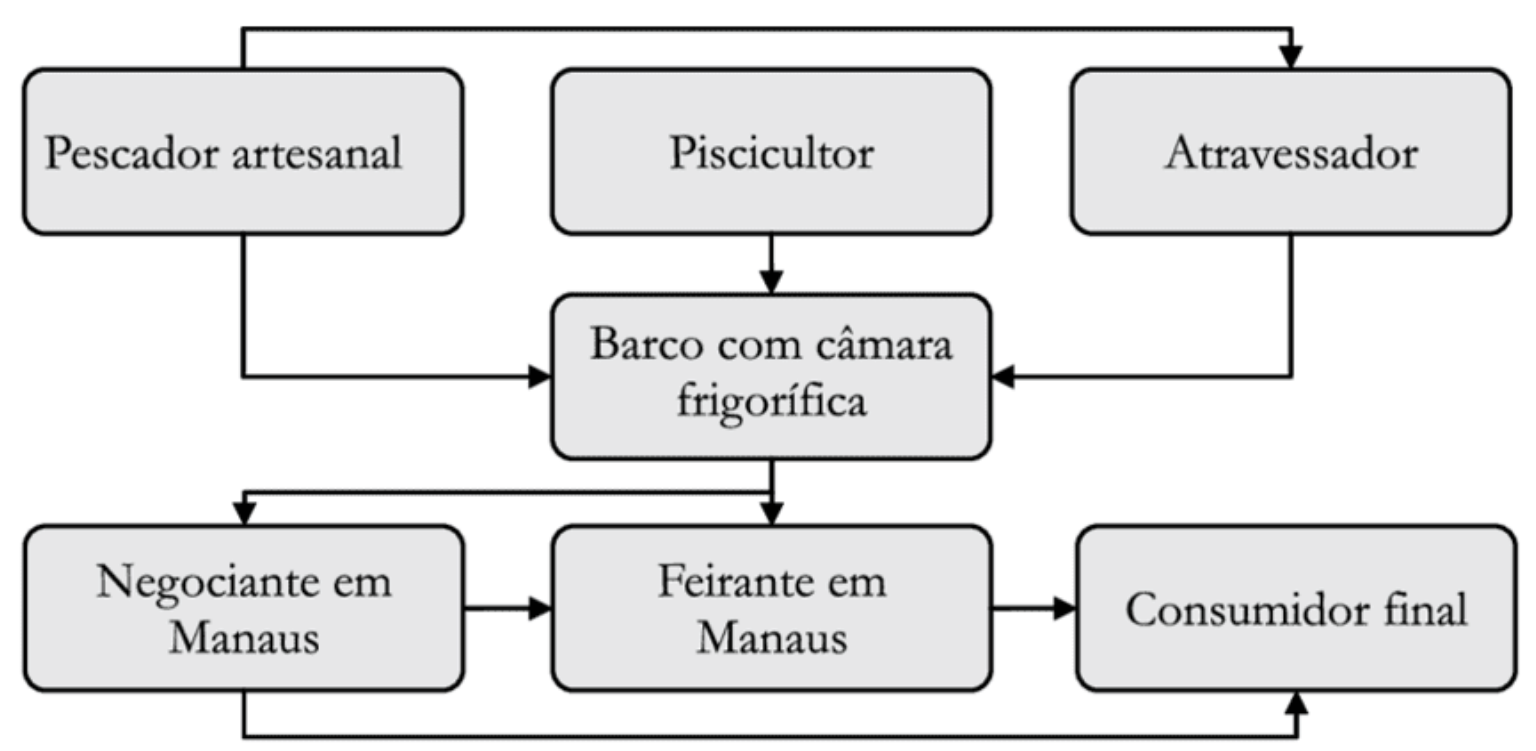

Fonte: Oliveira et al., (2010).

De acordo com Souza et al. (2015) o olhar contábil parte dos detalhes do micro, como componentes do preço que não são percebidos pelo pescador, no entanto influenciam diretamente no valor final ao consumidor e esse simples fato pode ser determinante para o fechamento das contas ao final do mês como solvente ou insolvente, ou seja, com crédito e lucro de sua ação ou com a realidade dura expressa por um mês de trabalho que não pagou aquilo que se gasta para ir aos rios pescar.

\section{MATERIAIS E MÉTODOS}

\subsection{PROCEDIMENTOS METODOLÓGICOS}

Segundo Cardano (2017) a metodologia de pesquisa são os procedimentos ou técnicas específicas usadas para identificar, selecionar, processar e analisar informações sobre um tópico. De acordo com Zanella (2013) em um artigo de pesquisa, a seção de metodologia permite ao leitor avaliar criticamente a validade e confiabilidade geral de um estudo. Sendo assim, o tópico de procedimentos

RC: 100892

Link de acesso: https://www.nucleodoconhecimento.com.br/contabilidade/recursospesqueiros 
metodológicos descreve-se as ações que foram tomadas na investigação do problema de pesquisa e a justificativa para que fosse possível aplicar os procedimentos ou técnicas específicas.

\subsection{QUANTO À NATUREZA}

De acordo com Cardano (2017) quanto a natureza, uma pesquisa pode ser classificada como básica ou aplicada. Segundo Koche (2015) o tipo de estudo aplicado se classifica como uma pesquisa por informações e dados que possam ser utilizados em prática, com objetivo de solucionar problemas do cotidiano. O presente estudo trata-se de uma pesquisa aplicada visto que o tema é abordado de forma mais profunda, com o alcance de resultados que possam permitir analisar e solucionar fatores que interagem com os processos da contabilidade no mercado de pesca.

\subsection{QUANTO AOS FINS}

Segundo Severino (2016) quanto aos fins, uma pesquisa pode ser classificada como exploratória, descritiva ou explicativa. De acordo com Santanche (2014) o estudo exploratório tem como finalidade apresentar mais dados sobre 0 assunto proposto, podendo gerar uma nova visão em relação aos aspectos que envolvem o tema abordado. Por isso, essa pesquisa trata-se de pesquisa exploratória, pois objetiva proporcionar uma visão geral do tema, aprofundando os conceitos básicos, possibilitando o esclarecimento das análises realizadas de formas superficiais sobre a influência que a contabilidade geral e identificar a viabilidade dessa implantação como ferramenta de gestão.

\subsection{QUANTO AOS MEIOS}

De acordo com Estrela (2017) os meios de pesquisa bibliográfica tornam-se necessária em todas as formas de pesquisas, pois é através dela que há possibilidade de conhecer os estudos existentes. Segundo Menezes et al. (2019)

RC: 100892

Link de acesso: https://www.nucleodoconhecimento.com.br/contabilidade/recursospesqueiros 
seu desenvolvimento é através de materiais já elaborados, como livros, artigos científicos, publicações de órgãos oficiais, principalmente e é na leitura dessas ferramentas que o conteúdo para a pesquisa é encontrado. Esse artigo utilizou-se como meio de pesquisa bibliográfico, pela possibilidade de analisar referências publicadas em documentos, com o recolhimento amplo de informações e conhecimentos prévios acerca do impacto e dos fatores relacionados à contabilidade e os recursos pesqueiros.

\section{CONSIDERAÇÕES FINAIS}

Diante do exposto e sendo levado em consideração os objetivos definidos para o desenvolvimento da pesquisa que foram estabelecidos como a identificação da necessidade da utilização da contabilidade na gestão dos recursos pesqueiros. Com a conclusão de que a utilização de ferramentas da contabilidade pode gerar inúmeros benefícios aos responsáveis pelo mercado pesqueiro. Foi possível compreender que o impacto dos recursos contábeis pode fornecer ainda mais rentabilidade em localidades como no Amazonas, onde a disponibilidade e variedades de recursos pesqueiros são abrangentes e o consumo de pescados da população local é elevado.

O presente trabalho buscou responder a seguinte questão: de que forma a contabilidade pode influenciar na organização da cadeia produtiva dos recursos de pequenos negócios pesqueiros no Amazonas? Com isso, buscou-se analisar diversos estudos que envolvem a perspectiva descrita na questão, onde foi compreendido que pode ser eficiente a aplicabilidade dessa ferramenta por ela possibilitar maior controle dos recursos, pois a contabilidade pode gerar maior controle e supervisão financeira dentro da cadeia dos pequenos negócios pesqueiros, principalmente para os pescadores locais, que em sua maioria são desprovidos de qualquer conhecimento sobre o controle financeiro que as ferramentas contábeis oferecem. 
Além disso, foi objetivado analisar os segmentos que compõem a cadeia produtiva do pescado e sua relação com processos contábeis. A cadeia de recursos pesqueiros pode possuir uma dinâmica como outras cadeias no comércio. Sendo considerada uma rede inter-relacionada de fornecedores e clientes, onde o fluxo de materiais e informações é coordenado em toda a cadeia. Sendo assim dada, a cadeia de recursos pesqueiros envolve conexões comerciais, gestão do desempenho operacional e negócios e torna necessário a aplicação de mecanismo contábeis, para que a funcionalidade da cadeia seja realizada de forma a obtenção de lucros.

Portanto, com a pesquisa realizada foi possível analisar e compreender que toda a cadeia de recursos pesqueiros, desde a pesca a liberação do produto para comercialização envolve procedimentos financeiros, o que com o suporte dos recursos contábeis pode se tornar um tipo de empreendimento crescente. Porém, também se faz necessário que mais estudos analíticos sejam realizados para que uma maior comprovação desse contexto seja realizada. Para assim chamar a atenção das autoridades locais para que desenvolvam um tipo de programa de treinamento que possa conscientizar e educar os pescadores quando a importância de uma boa gestão contábil para o crescimento financeiro.

\section{REFERÊNCIAS}

ALMEIDA, Jose. Fundamentos de Contabilidade para os Negócios: introdução à contabilidade. Elsevier Brasil, 2016.

ALVARADO, David Jiménez. La pesca recreativa en Canarias: aspectos principales y Evolución. 2016. Tese de Doutorado. Universidad de Las Palmas de Gran Canaria.

ALVES, Robson. A teoria da contabilidade. Londrina: Editora e Distribuidora Educacional S.A., 2017. p. 9. 
AZEVEdO, Natália Tavares de. Política Nacional Para o Setor Pesqueiro no Brasil (2003-2011). 2012, 349f. Tese (Doutorado em Meio Ambiente e Desenvolvimento). Programa de Pós-Graduação Meio Ambiente e Desenvolvimento, Universidade Federal do Paraná, Curitiba, 2012.

BIRK, Mariana; FEDATO, Geovana Alves De Lima; PIRES, Vanessa Martins. Os artefatos contábeis (re) produzidos pela academia para os pequenos negócios. Revista da Micro e Pequena Empresa, v. 14, n. 3, p. 105, 2020.

BRASIL. Lei n. 11.958, de 26 de junho de 2009. Brasília, 2009.

BUGARIM, M.; OLIVEIRA, O. A Evolução da Contabilidade no Brasil: Legislações, órgão de Fiscalização, Instituições de Ensino e Profissão. XI Simpósio de Excelência em Gestão e Tecnologia-SEGet, 2014.

CADIMA, Emygdio L. Manual de avaliação de recursos pesqueiros. Food \& Agriculture Org., 2000.

CARDANO, Mario. Manual de pesquisa qualitativa. Uma contribuição da teoria da argumentação Petrópolis: Vozes, 2017.

CARNEIRO, Henrique. Comida e sociedade: uma história da alimentação. Elsevier Brasil, 2017.

CHUPEL, Jéssica Fernanda; SOBRAL, Elvio; BARELLA, Lauriano Antonio. A importância da contabilidade para microempreendedor individual. Revista Eletrônica da Faculdade de Alta Floresta, v. 3, n. 2, 2014.

DE OLIVEIRA MORAES, André; SCHOR, Tatiana; ALVES-GOMES, José Antônio. Relações de trabalho e transporte na pesca de bagres no rio Solimões-AM. Novos Cadernos NAEA, v. 13, n. 1, 2010.

ESTRELA, Carlos. Metodologia científica: ciência, ensino, pesquisa. Artes Médicas, 2018.

RC: 100892

Link de acesso: https://www.nucleodoconhecimento.com.br/contabilidade/recursospesqueiros 
FONSECA, Reinaldo Aparecida et al., A importância do contador nas organizações. Simpósio de excelência em gestão e tecnologia, v.11, 2014.

FREITAS, Clodoaldo OLIVEIRA et al. Gestão Custos da Colônia de Pescadores Z-3 do Vale do Guaporé-RO. In: Anais do Congresso Brasileiro de Custos-ABC. 2016.

KÖCHE, José Carlos. Fundamentos de metodologia científica. Editora Vozes, 2016.

LAKATOS, Eva Maria. Fundamentos de Metodologia Científica. 8. Ed. São Paulo: Atlas, 2017.

LEITE, Tarcio Murilo Ferreira. MATOS, Giovani Cliffeson Da Silva. ARAÚJO, Jamille Carla Oliveira. Gestão de custos e gerenciamento de caixa para pescadores da associação Z8 do Município de São João De Pirabas- PA. Revista Científica Multidisciplinar Núcleo do Conhecimento. 2019.

MENEZES, Afonso Henrique Novaes et al. Metodologia científica: teoria e aplicação na educação a distância. Universidade Federal do Vale do São Francisco, Petrolina-PE, 2019.

PAIVA, Eliabe De Passos De et al. A Utilidade Da Contabilidade: Um estudo realizado sobre o ponto de vista dos Microempreendedores Individuais. 2020.

PEREIRA, Marcel Perez et al. Descrição do sistema agroindustrial brasileiro de pescado. Informações Econômicas, v. 40, n. 3, p. 53-61, 2010.

PINHEIRO, Maria L. da S. et al. Cadeia produtiva do pescado no Estado do Para: estudo do segmento de distribuição em um empreendimento de captura. Revista em Agronegócio e Meio Ambiente, 2014.

SANTANCHE, André. Metodologia ciências e normas técnicas. Salvador: UNIFACS, 2014.

RC: 100892

Link de acesso: https://www.nucleodoconhecimento.com.br/contabilidade/recursospesqueiros 
SANTOS, Patrick Heleno et al. Contabilidade Na Amazônia: O Desafio De Analisar Uma Cadeia Produtiva Extrativista. Observatorio de la Economía Latinoamericana, n. 221, 2016.

SANTOS, Marco Pais Neves et al. A pesca enquanto atividade humana: pesca artesanal e sustentabilidade. Revista de Gestão Costeira Integrada-Journal of Integrated Coastal Zone Management, v. 12, n. 4, p. 405-427, 2012.

SCHNEIDER, Maurício. Fauna e recursos pesqueiros na legislação brasileira. Conservação da Biodiversidade: Legislação e Políticas Públicas. Ganem RS,(org.)-Brasília: Câmara dos Deputados, Edições Câmara, p. 294-5, 2010.

SEVERINO, Antônio Joaquim. Metodologia do trabalho científico. Cortez editora, 2017.

SILVA PINHEIRO, Maria Liduína et al. Cadeia Produtiva do Pescado no Estado do Pará: Estudo do Segmento de Distribuição em um Empreendimento de Captura. Revista em Agronegócio e Meio Ambiente, v. 7, n. 2, 2014.

SERVERINO, Joaquim Antônio. Metodologia Do Trabalho Científico - 24를 - São Paulo. Ed: Cortez, 2016. p. 90.

SILVEIRA, Fernando Alves; CARDOSO, Amilde Adilio; COSTA, Erico Souza. Blockhain E A Contabilidade Bna Era Digital: Desafios Ou Oportunidade. Seminário de ciências sociais aplicadas, v.6, n.6, 2018.

SOUZA, Adriana Pantoja et al. IMPACTO DA ADOÇÃO DAS IFRSS NAS EMPRESAS EXPORTADORES DO PESCADO NO PARÁ: uma análise a partir da percepção dos contadores que atuam no setor. Revista de Administração e Contabilidade-RAC, v. 2, n. 4, 2015. 
SOUZA, Rony Willams Frutuoso. Estudo das relações de trabalho entre os pescadores comerciais e a cadeia de comercialização dos bagres em uma comunidade rural na região de Manacapuru-AM. 2010. Relatórios finais de Iniciação Científica UFAM.

VERGARA, Silvia Constant. Projetos e Relatórios de Pesquisa em Administração. 16. Ed. São Paulo: Atlas, 2016.

VIANA, João Paulo. Recursos pesqueiros do Brasil: situação dos estoques, da gestão e sugestões para o futuro. 2013. Boletim Regional Urbano e ambiental do Instituto de Pesquisa Econômica Aplicada (Ipea).

YAMAMOTO, Kedma Cristine et al. A cadeia produtiva de peixes ornamentais no estado do Amazonas. Revista Ibero-Americana de Ciências Ambientais, v. 12, n. 2, 2021.

ZANELLA, Liane Carly Hermes. Metodologia de Pesquisa. 2. Ed. reimp Florianopólis: UFSC, 2013.

Enviado: Outubro, 2021.

Aprovado: Novembro, 2021. 